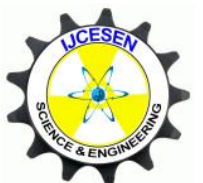

Copyright (C) IJCESEN
International Journal of Computational and

Experimental $\boldsymbol{S}$ cience and $\boldsymbol{E N g i n e e r i n g}$

(IJCESEN)

Vol. 5-No.1 (2019) pp. 31-36

http://dergipark.gov.tr/ijcesen

Research Article

\title{
Effect of Change in Radial Clearance on Pressure Variation of Fluid in Hydrodynamic Journal Bearing
}

\section{Iredia ERHUNMWUN*, John AKPOBI}

University of Benin, Faculty of Engineering, Department of Production Engineering, Benin City, Nigeria

* Corresponding Author : iredia.erhunmwun@uniben.edu ORCID: 0000-0002-0497-8220

\section{Article Info:}

DOI: $10.22399 /$ ijcesen.492548

Received : 05 December 2018

Accepted : 14 February 2019

\section{$\underline{\text { Keywords }}$}

Hydrodynamic lubrication

Journal bearing

Weak formulation

Radial clearance

Finite Element Method

\begin{abstract}
$\underline{\text { Abstract: }}$
This work entails the parametric study of the effect of the change in bearing radial clearance with pressure variation of the fluid (lubricant) in a hydrodynamic journal bearing was carried out. The classical Reynolds Equation was used to represent the pressure behaviour in the bearing. This study was carried out using the Galerkin Finite Element Method (GFEM). The result obtained shows that the pressure increases from the ambient pressure which is taken to be zero and increases significantly till $145.3737^{\circ}$. At this point, the pressure is maximum with $1.955 \mathrm{MPa}$ and then drop until it gets to $180^{\circ}$ where the pressure equals the ambient pressure. Between angular displacements of $180^{\circ}$ and $360^{\circ}$ there were also pressure variations which were equal in magnitude with those between $0^{\circ}$ and $360^{\circ}$ but with different direction. From the foregoing, it is observed that as the radial clearance increases, the pressure in the bearing drops significantly. Therefore, in the design of journal bearings, the radial clearance should a high as possible to reduce the pressure in the bearing. The result obtained shows a strong positive correlation with existing result in literature.
\end{abstract}

\section{Introduction}

In hydrodynamic bearing, the fluid film separates the bearing and journal and thus permits a relative motion between the contacts surfaces with minimal friction. This fluid film reduces the wear of machine elements and also carries away the generated heat [1]. Clearance between the journal and bearing shells is the most important factors when it comes to the health and durability of assembly because that open area is filled with oil which provides a cushion between the journal itself and the bearing [2]. A few micron variations in the clearance may cause serious changes in different performance parameters of the bearing [3]. This important parameter can be managed at three stages of bearing life cycle such as designing, manufacturing and usage [4]. Ocvfik et al. [5] scrutinized the effect of bearing-clearance on the friction power loss, the film thickness, and the peak pressure in the oil film. They reported that the load capacity passes through a maximum value at a small bearing clearance and then decreases with increasing bearing clearance. Mitsui et al [6] concluded that with the decrease of clearance ratio, there is an increment in the maximum bearing temperature, speed and lubricant viscosity. Prashad et al. [7] presented the effects of viscosity and clearance on the performance of hydrodynamic Journal Bearings. The higher clearance leads to an increase in the axial flow rate particularly under high applied loads and high rotational speeds [8]. El-Kersh et al. [9] analyzed the effect of thermal expansion on three polymer composite journal bearings at different rotational speeds and clearance ratio. They found that, the increase of bearing clearance ratio leads to increase the friction coefficient and minimum oil film thickness and at the same time reduces the maximum bearing temperature and load carrying capacity. Similar observations were made by [10]. They scrutinized the counter rotating floating ring journal under 
different working conditions. Their investigation revealed that by decreasing the radii ratio $(\mathrm{R} 2 / \mathrm{R} 1)$ of the ring and clearance ratio $(\mathrm{C} 1 / \mathrm{C} 2)$, the coefficient of friction decreases at the same time, with this the load carrying capacity of the bearing increases. Gangrade et al. [11] found that the performance of hydrodynamic journal bearing is mainly affected by clearance ratio, aspect ratio and speed. Amit et al. [12] investigated the effect of clearance on pressure distribution and fluid film thickness of fluid film journal bearing. The behavior of these performance parameters at different relative clearance in circumferential and axial direction is scrutinized. Simmsons et al. [13] showed that the results for the large clearance configurations did not show the dramatic variation in maximum bearing temperature associated with a transition from laminar to turbulent cooling that was found for standard clearance cases. Papadopoulos et al. [14] theoretically presented the identification of clearances and stability analysis for a rotor journal bearing system using response measurements of the rotor at a particular point i.e the midpoint of the rotor. The measurements should be taken at two different speeds and from different wear effects. This present work also verified experimentally from the previous work. [4] studied on the journal bearing performances and metrology issues. In this experimental study out--of-roundness and radial clearance of journal bearings were measured with high precision and the impact of their metrology was examined on the specific oil film thickness of the bearing. Results showed that the radial clearance measurements can vary from one measuring device to another and the specified clearance may not necessarily meet the design criteria of specific oil film thickness. Tian et al. [15] examined the effect of bearing outer clearance on dynamic behavior of full floating ring and observed that the stability could be enhanced by increasing clearance. Fargere et al. [16] examined that the alignment of the shaft can be modified by changing the bearing clearance. Harpreet et al. [17] theoretically examine the influence of clearance parameter on the non-dimensional values of pressure distribution and static performance parameter for the bearing operating under three different values of clearance parameter. Mane et al. [18] presented a paper on the 3D model of hydrodynamic plain journal bearing using COMSOL Multiphysics 4.3a software.

In all the literatures reviewed so far, there is no general analytic solution to the classical Reynolds Equation that models the effect of side or end leakage; however, approximate solutions have been obtained by using electrical analysis, mathematical summations, relaxation methods and numerical and graphical methods [19]. This study is presented to investigate the effect of change in radial clearance with the pressure distribution in a journal bearing under hydrodynamic lubrication assuming that the bearing is infinitely short.

\section{Governing Equation and boundary conditions}

The governing Equation for pressure variation in an infinitely short hydrodynamic journal bearing is shown thus:

$$
\frac{\partial}{\partial z}\left(\frac{h^{3}}{\mu} \frac{\partial P}{\partial z}\right)=6 U \frac{\partial h}{\partial x}
$$

where $\mathrm{P}=$ pressure, $\mathrm{z}=$ Axial direction, $\mathrm{h}=$ Film Thickness, $\mu=$ Lubricant viscosity, $\mathrm{x}=$ Circumferential direction, $\mathrm{U}=$ Linear velocity

Eq. 1 is the well-known Reynolds Equation for a bearing that is assumed to be infinitely short. This Equation is subject to the following set of initial and boundary conditions.

$$
P(\theta, 0)=P(\theta, L)=0
$$

where $\theta=$ Angular displacement, $\mathrm{L}=$ Length of the bearing

For symmetry reasons,

$$
\left.\frac{\partial P}{\partial z}\right|_{z=0}=0
$$

The domain of the problem consists of all points between $z=0$ and $z=L$ i.e. $\Omega=(0, L)$. The domain was divided into a set of line elements, a typical element being of length $h_{e}$ and located between two arbitrary points A and B. The collection of such elements is called the finite element mesh of the domain. The reason for dividing the domain into finite elements was to represent the geometry of the domain and to approximate the solution over the entire domain.

\section{Mathematical analysis}

In the development of the weak form, we assumed a linear mesh and placed it over the domain. This was done by multiplying Eq. 1 by the weighted function (w) and integrating the final Equation over the domain. This results in the mathematical expression in Eq. 4.

$$
\int_{z_{A}}^{z_{R}} \frac{h^{3}}{\mu} \frac{\partial w}{\partial z} \frac{\partial P}{\partial z} d z+\int_{z_{A}}^{z_{R}} 6 w U \frac{\partial h}{\partial x} d z-w Q_{A}-w Q_{B}=0
$$


Eq. 4 is known as the weak form of the governing equation for hydrodynamic lubrication in journal bearing.

The weak form requires that the approximation chosen for $P$ should be at least linear in $z$ so that there are no terms in eq. 4 that are identically zero. Since the primary variable is simply the function itself, the Lagrange family of interpolation functions is admissible. We proposed that $P$ is the approximation over a typical finite element domain by the expression:

$$
P^{e}=\sum_{j=1}^{n} P_{j}^{e} \psi_{j}^{e}(z) \text { and } w=\psi_{i}^{e}(z) \quad i, j=1,2,3
$$

where $w=\psi_{i}^{e}(z)$ is the trial function

In Galerkin's weighted residual method, the weighting functions are chosen to be identical to the trial functions [20].

Substitute eq. 5 into eq. 4 , we have:

$$
\begin{aligned}
& \frac{h^{3}}{\mu}\left[K_{i j}^{e}\right]\left\{P_{j}^{e}\right\}=-6 U \frac{\partial h}{\partial x}\left\{F_{i}^{e}\right\}+\left\{Q_{i}^{e}\right\} \\
& \text { where } K_{i j}^{e}=\int_{z_{A}}^{z_{\beta}} \frac{\partial \psi_{i}^{e}(z)}{\partial z} \frac{\partial \psi_{j}^{e}(z)}{\partial z} d z \\
& \begin{array}{c}
\text { assembling } g_{i}^{z} \text { we have: } \\
F_{i}^{e} \psi_{i}^{e}(z) d z \\
z_{A}
\end{array} \\
& Q_{i}^{e}=\psi_{i}^{e}(z) Q_{A}+\psi_{i}^{e}(z) Q_{B}
\end{aligned}
$$

Eq. 6 is referred to as the finite element based model, eq. 7 is known as the bearing matrix and eq. 8 is referred to as the wedge matrix.

Hence, the one-dimensional Lagrange quadratic interpolation function for Equation becomes

$$
\begin{gathered}
\psi_{1}=\left(1-\frac{z}{h_{e}}\right)\left(1-\frac{2 z}{h_{e}}\right), \\
\psi_{2}=\frac{4 z}{h_{e}}\left(1-\frac{z}{h_{e}}\right), \quad(10) \\
\psi_{3}=-\frac{z}{h_{e}}\left(1-\frac{2 z}{h_{e}}\right)
\end{gathered}
$$

where $h_{e}=$ Elemental length of the bearing

3.1. Evaluating the bearing matrix $\left\lfloor K_{i j}\right\rfloor$ and wedge matrix $\left\{F^{e}\right\}$ for journal bearing
To evaluate the $K_{i j}$ matrix, we substitute eq. 10 accordingly into eqs. 7 and 8 respectively, we have;

$$
\begin{aligned}
& K^{e}=\frac{1}{3 h_{e}^{3}}\left[\begin{array}{ccc}
7 h_{e}^{2}-24 h_{e} z_{A}+48 z_{e}^{2} & -8\left(h_{e}^{2}-3 h_{e} z_{A}+12 z_{e}^{2}\right) & h_{e}^{2}+48 z_{A}^{2} \\
\left.-3 z_{A} z_{A}+12 z^{2}\right) & 16\left(h_{e}^{2}+12 z_{A}^{2}\right) & -8\left(h_{e}^{2}+3 h_{e} z_{A}+12 z_{A}^{2}\right) \\
h_{e}^{2}+48 z_{A}^{2} & -8\left(h_{e}^{2}+33 z_{e} z_{A}+12 z_{A}^{2}\right) & 7 h_{e}^{2}+24 h h_{e} z_{A}+48 z_{e}^{2}
\end{array}\right] \\
& F=\left\{\begin{array}{l}
\frac{h_{e}}{6}-z_{A}+\frac{2 z_{A}^{2}}{h_{e}} \\
\frac{2\left(h_{e}^{2}-6 z_{A}^{2}\right)}{3 h_{e}} \\
\frac{h_{e}}{6}+z_{A}+\frac{2 z_{A}^{2}}{h_{e}}
\end{array}\right\}
\end{aligned}
$$

Eq. 11 represents the generalized form of the bearing matrix for the entire domain of the bearing and eq. 12 it represents the generalized form of the wedge matrix for the entire domain of the bearing..

In our analysis, the bearing domain was divided into four quadratic elements as shown in Figure 1.

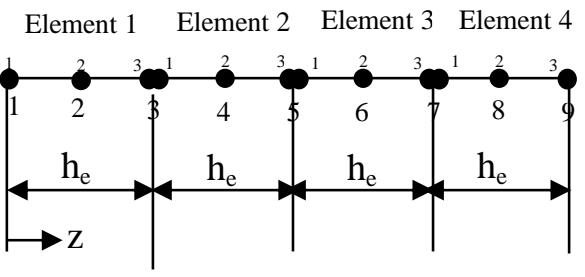

Figure 1: A four quadratic element

Analysing the elements part by part and finally

$\left[K^{e}\right]=\frac{1}{3 h_{e}}\left[\begin{array}{ccccccccc}7 & -8 & 1 & 0 & 0 & 0 & 0 & 0 & 0 \\ -8 & 16 & -8 & 0 & 0 & 0 & 0 & 0 & 0 \\ 1 & -8 & 38 & -80 & 49 & 0 & 0 & 0 & 0 \\ 0 & 0 & -80 & 208 & -128 & 0 & 0 & 0 & 0 \\ 0 & 0 & 49 & -128 & 230 & -344 & 193 & 0 & 0 \\ 0 & 0 & 0 & 0 & -344 & 784 & -440 & 0 & 0 \\ 0 & 0 & 0 & 0 & 193 & -440 & 614 & -800 & 433 \\ 0 & 0 & 0 & 0 & 0 & 0 & -800 & 1744 & -944 \\ 0 & 0 & 0 & 0 & 0 & 0 & 433 & -944 & 511\end{array}\right]$

$$
\left\{F^{e}\right\}=\frac{h_{e}}{6}\left\{\begin{array}{c}
1 \\
4 \\
8 \\
-20 \\
56 \\
-92 \\
152 \\
-212 \\
127
\end{array}\right\}
$$

Substitute in eq. 6, eqs. 13 and 14 and finally, substituting the boundary conditions in eqs. 2 and 3 and also these parameters $h_{e}=L / 4, U=\omega r$, $x=r \theta$ and $h=c(1+\varepsilon \cos \theta)$, we have: 


$\left[\begin{array}{ccccccc}16 & -8 & 0 & 0 & 0 & 0 & 0 \\ -8 & 38 & -80 & 49 & 0 & 0 & 0 \\ 1 & -80 & 208 & -128 & 0 & 0 & 0 \\ 0 & 49 & -128 & 230 & -344 & 193 & 0 \\ 0 & 0 & 0 & -344 & 784 & -440 & 0 \\ 0 & 0 & 0 & 193 & -440 & 614 & -800 \\ 0 & 0 & 0 & 0 & 0 & -800 & 1744\end{array}\right]\left\{\begin{array}{l}P_{2} \\ P_{3} \\ P_{4} \\ P_{5} \\ P_{6} \\ P_{7} \\ P_{8}\end{array}\right\}=\frac{3 \omega L^{2} \mu \varepsilon \sin \theta}{16 c^{2}(1+\varepsilon \cos \theta)^{3}}\left\{\begin{array}{c}4 \\ 8 \\ -20 \\ 56 \\ -92 \\ 152 \\ -212\end{array}\right\}$

where $\mathrm{L}=$ Length of Bearing, $\mathrm{U}=$ Linear velocity, $\omega=$ Angular velocity, $\mathrm{r}=$ radius of bearing, $\mathrm{c}=$ radial clearance, $\varepsilon=$ eccentricity ratio

\section{Results and Discussion}

The parameters used in this analysis is as shown in Table 1.

Table 1. Parameters for calculation for short journal

\begin{tabular}{|c|c|}
\hline \multicolumn{2}{|c|}{ bearing [18] } \\
\hline Parameters & Short bearing \\
\hline Lengths of bearing & $2.50 \times 10^{-2}(\mathrm{~m})$ \\
\hline Diameter of journal & $0.05(\mathrm{~m})$ \\
\hline Radial clearance & $2.50 \times 10^{-5}(\mathrm{~m})$ \\
\hline Eccentricity & $1.25 \times 10^{-5}(\mathrm{~m})$ \\
\hline Eccentricity ratio & 0.50 \\
\hline Speed of journal & $1000(\mathrm{rpm})$ \\
\hline Dynamic viscosity of oil & $0.19(\mathrm{~Pa} . \mathrm{S})$ \\
\hline Inlet temperature & $315(\mathrm{~K})$ \\
\hline
\end{tabular}

\subsection{Variation of pressure with angular displacements for journal bearing}

The results obtained for the variation of pressure with angular displacements for a hydrodynamically loaded journal bearing which was assumed to be infinitely short is as shown in Figure 2. In the infinitely short journal bearing condition, it was assumed that there was no side leakage. The nodal values were the pressures at those points on the bearing. The graph shown was in a sinusoidal wave form. P1 to P9 shows the pressure distribution at the various nodes from 1 to 9 respectively. A combination of both the Neumann and Dirichlet boundary conditions was used. From the boundary conditions used, the pressure increases from the ambient pressure which was taken to be zero at an angular displacement of $0^{0}$ and increases significantly till $145.3737^{0}$ where the pressure becomes maximum with $1.9955 \mathrm{MPa}$. Thereafter, it began to drop until it gets to $180^{\circ}$ where the pressure became the same as the ambient pressure. From this point onward, we began to experience negative pressure. The negative pressures in this regard were those that were below the ambient pressure. At this point, cavity began to set in. This pressure increases in the negative direction till $210.6262^{\circ}$ and back again to the ambient pressure at $360^{\circ}$. Then, another cycle began between $360^{\circ}$ and $720^{\circ}$ and so on.

Note that this research was carried out at a constant inlet temperature of $315 \mathrm{~K}$ as shown in Table 1 above.

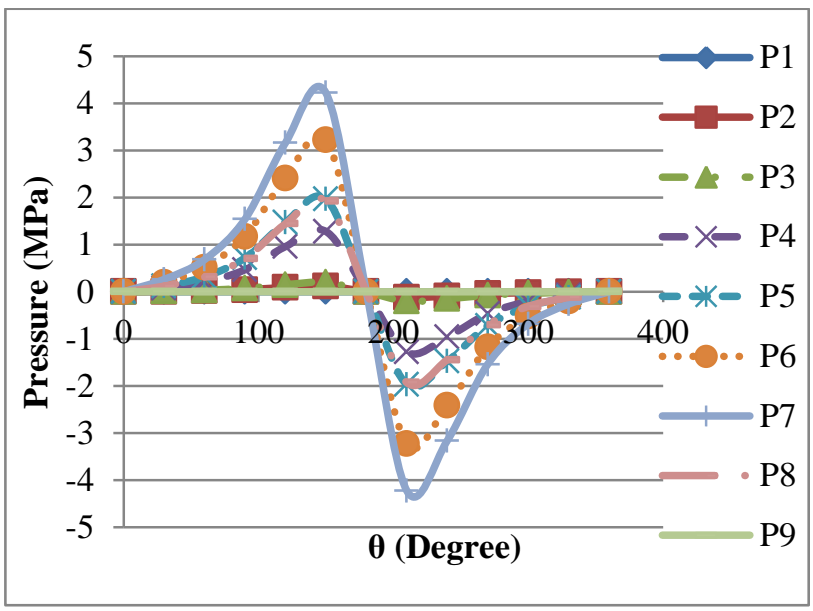

Figure 2. A graph of all the pressures against angular displacement

The result from FEM was validated by comparing it with the result from the analytical solution and the result published by [18]. The comparison shows a strong positive correlation. The FEM approximates the solution to the analytical solution better than the result by [18]. This is shown in Table 2 .

Table 2: Comparison between FEM, COSMOL and Analytical solution

\begin{tabular}{|c|c|c|c|}
\hline $\mathrm{Q}\left({ }^{0}\right)$ & ANALYTICAL & COSMOL & FEM \\
\hline 0 & 0 & 0 & 0 \\
\hline 30 & 122565 & 120231 & 122000 \\
\hline 60 & 317565 & 315456 & 318375 \\
\hline 90 & 718245 & 717546 & 718023 \\
\hline 120 & 1491345 & 1415657 & 1473959 \\
\hline 150 & 2003459 & 1954563 & 1969648 \\
\hline 180 & 0 & 0 & 0 \\
\hline 210 & -2003459 & -1954563 & -1969648 \\
\hline 240 & -1491345 & -1415657 & -1473959 \\
\hline 270 & -718245 & -717546 & -718023 \\
\hline 300 & -317565 & -315456 & -318375 \\
\hline 330 & -121565 & -120231 & -122000 \\
\hline 360 & 0 & 0 & 0 \\
\hline
\end{tabular}

\subsection{Pressure variation with change in radial clearance}


In hydrodynamic bearing, the fluid film separates the bearing and journal and thus permits a relative motion between the contacts surfaces with minimal friction. This fluid film reduces the wear of machine elements and also carries away the generated heat. Clearance between the journal and bearing shells is the most important factors when it comes to the health and durability of assembly because that open area is filled with oil which provides a cushion between the journal itself and the bearing. A few micron variations in the clearance may cause serious changes in different performance parameters of the bearing. This important parameter can be managed at three stages of bearing life cycle such as designing, manufacturing and usage.

The graph showing the variation of pressure with change in radial clearance is shown in Figure 3. From Figure 3, the range of radial clearance used is between $0.000005 \mathrm{~m}$ and $0.0001 \mathrm{~m}$. From the foregoing, it is observed that as the radial clearance increases, the pressure in the bearing drops significantly. Therefore, in the design of journal bearings, the radial clearance should a high as possible to reduce the pressure in the bearing.

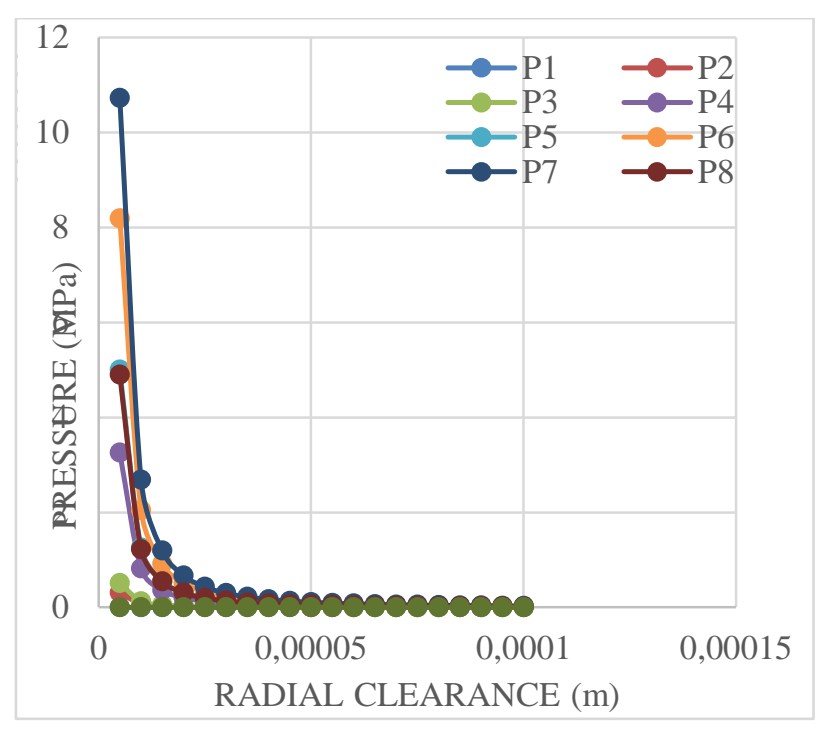

Figure 3. Variation of pressure with radial clearance

\section{Conclusion}

The pressure distribution of the hydrodynamic journal bearing lubricated with oil under steady state and constant temperature consideration has been analysed. Based on the results and discussion presented in the preceding section, the following conclusions can be reached.

The Finite Element Method (FEM) form of the general governing Reynolds Equation was derived and implemented for hydrodynamic journal bearing. Using Reynolds Equation, a numerical solution has been developed for short journal bearing under steady state. The finite element method provides the node by node results for pressure distribution. Using FEM, the result obtained was compared with COSMOL and analytical solution. It was found that FEM gives approximately identical solution for short journal bearing.

From the foregoing, it is observed that as the radial clearance increases, the pressure in the bearing drops significantly. Therefore, in the design of journal bearings, the radial clearance should a high as possible to reduce the pressure in the bearing.

\section{References}

[1] P. Tiwari and V. Kumar. Analysis of Hydrodynamic Journal Bearing: A Review, International Journal of Engineering Research and Technolology, 1, 7, ESRSA Publications, 2012.

[2] B. V. Bhandari. Design of Machine Elements, 3rd Edition, Tata Mcgraw Hill Education Private Ltd. New Delhi, India, ISBN-13: 978-0-07-068179-8, 2010.

[3] S. P. Chu and E. Kay. Optimum Clearance Fits for Journal Bearings in Relation to BS 1916 and to Lubrication Theory, Wear, 27, 3, 329-343, 1974.

[4] S. Sharma, D. Hargreaves and W. Scott. Journal bearing performance and metrology issues. Journal of Achievements in Materials and Manufacturing Engineering 32, 1, 98-103, 2009.

[5] W. F. Ocvfik and B. G. D'ubois. Relation of Journal Bearing Performance to minimum oil film, NACA, TN 4223, 1958.

[6] J. Mitsui, Y. Hori and M. Tanaka. An Experimental Investigation on the Temperature Distribution in Circular Journal Bearings, ASME Journal of Tribology 108, 4, 621- 626, 1986.

[7] H. Prashad. The Effects of Viscosity and Clearance on the Performance of Hydrodynamic Journal Bearings, Tribology Transactions. 31, 2, 303-309, 1988.

[8] I. Pierre and M. Fillon. Influence of Geometric Parameters and Operating Conditions on the Thermohydrodynamic Behavior of Plain Journal Bearings" Proc. of the Institution of Mechanical Engineers, Part J: Journal of Engineering Tribology, France, Sage publication, 214, 5, 445457, 2000.

[9] A. M. El-Kersh and W. Y. Ali. The effect of thermal expansion and elastic deformation on the performance of polyamide-copper journal bearings, KGK Kautschuk Gummi kunststoffe, 54, (9), 468473, 2001.

[10] B. A. Abass, A. A. Alwan and M. B. Hunain. An Investigation into the Performance of Counter Rotating Floating Ring Journal Under Different Working Conditions, Al-Khwarizmi Engineering Journal,3,1, 26-39, 2007. 
[11] A. K. Gangrade and V. M. Phalle. Effect of Clearance and Aspect Ratio On The Performance Of Water Lubricated Hydrodynamic Journal Bearing, International Journal of Global Technology. Initiatives, 5, 1, D59-D64, 2016.

[12] M. Amit, R. K. Awasthi, S. S. Sarabjeet, D. Sandeep and S. Harpuneet. CFD Investigation of Clearance on Pressure Distribution and Fluid Film Thickness in Hydrodynamic Journal Bearing, International Journal of Advance Research and Innovation, Volume 4, Issue 2 571-575, 2016.

[13] J. E. L. Simmsons and S. J. Dixon. Effect of load direction, preload, clearance ratio, and oil flow on the performance of a $200 \mathrm{~mm}$ journal pad bearing" Tribology Transactions, 37, 227-236, 1994.

[14] A. C. Papadopoulos, G. Nikolakopoulos and D. Gounaris. Identification of clearances and stability analysis for a rotor-journal bearing system, Mechanism and Machine Theory, 43, 411-426, 2008.

[15] L. Tian, W. J. Wang and Z. J. Peng. Effects of bearing outer clearance on the dynamic behaviours of the full floating ring bearing supported turbocharger rotor, Mechanical Systems and Signal Processing, 31, 155-175, 2012.

[16] R. Fargere and P. Velex. Influence of clearances and thermal effects on the dynamic behavior of gearhydrodynamic journal bearing systems, ASME Journal of Vibration and Acoustics, 135, 061014-1061014-16, 2013.

[17] S. B. Harpreet, P. Gobind, R. K. Awasthi, S. M. Manjeet, S. Davinder, S. Navneet, K. Vijay and E. K. Keshwer. Impact of clearance contact on the performance of hydrodynamic journal bearing system, International Journal of Advance Research and Innovation, Volume 5, 1, 110-114, 2017.

[18] R. M. Mane and S. Soni. Analysis of hydrodynamic plain journal bearing. Excerpt from the proceedings of the 2013 COSMOL Conference in Bangalore.

[19] G. R. Budynas and K. J. Nisbett. Shigley's Mechanical Engineering Design, 10th Edition, McGraw- Hill Education, New York, ISBN 978-007-339820-4. 2015.

[20] J. N. Reddy, Introduction to the Finite Element Method, Second edition, McGraw-Hill series in Mechanical Engineering. 1993. 